\author{
International Journal of Modern Trends in \\ Social Sciences (IJMTSS) \\ Journal Website: http://ijmtss.com/ \\ eISSN: $2600-8777$
}

\title{
SOCIAL MEDIA RECRUITMENT: IN JOB FINDINGS AMONG THE GENERATION Y (FRESH GRADUATES)
}

\author{
Lingkeswari A/P Kunasagaram ${ }^{1}$, Christina Rathy A/P Anthony Samy ${ }^{2}$ \\ 1 School of Business \& Communication, Inti International College Subang Jaya \\ Email: lingkeswari.kunasagaram@newinti.edu.my \\ 2 School of Business \& Communication, Inti International College Subang Jaya \\ Email: christina.rathy@newinti.edu.my
}

\section{Article Info:}

\section{Article history:}

Received date: 15.01 .2020

Revised date: 21.01 .2020

Accepted date: 30.01 .2020

Published date: 15.03.2020

\section{To cite this document:}

Kunasagaran, L., \& Anthony Samy, C. R. (2020). Social Media Recruitment: In Job Findings among The Generation Y (Fresh Graduate). International Journal of Modern Trends in Social Sciences, 3 (11), 1333.

DOI: $10.35631 /$ IJMTSS.311002.

\begin{abstract}
:
The social media phenomenon has opened new paths of engagement and revolutionized the exchange of information. With more people engaging with social media, it is worth investigating its relevance to the recruitment process. The purpose of this paper is to assess how employers can make the best use of social media as part of the recruitment process. It examines which platforms effective suited to hosting job search information, which can help achieve recruitment goals and how candidates are used social media recruitment as a job finding tool. As the research examines a number of key questions on the current new ways of recruiting and its effectiveness, advantages such as accessibility and its impact on management. It analyzes the relationship between social media and recruitment and its impacts. There has been a relative research recommendation on exploring the processes and procedures individuals and employee organizations utilize with respect to employing social media in the workplace in the future, and specifically within the recruitment process. The findings confirm a dual-use of social media by employers, connected with a belief that strengthened connections with potential applicants are possible, alongside the original intended use as an attraction tool. It has also resulted in this research a significant positive relationship among social media recruitment as first would be Facebook is efficient and effective. This research concludes by highlighting a need for further research and recommendations for HRM practice.
\end{abstract}

Keywords:

Social Media Recruitment, Social Sites as Facebook, LinkedIn 


\section{Introduction}

\section{Background to the Study}

The Global Rise of Social Networks Brings a Brave New World 2.0 in this timeline. The new world with fast-changing technologies and these changes and open new opportunities for companies to communicate and work (Diaby,2014 pp46). Because of this constant change of technology, the phenomenon of Web 2.0 has occurred history and evolution of social networks in recruitment to social media recruitments as LinkedIn, Facebook, and websites for employees in Job findings.

The surfs of the internet this year are young people who define as Generation Y1 who grows up with computer, smartphones or tablets which known for employee daily use (Yeaton, 2017). The generation Y1 is well known as Millennials in the Workplace which outsource social networking to identify, attract, occupy and hire potential candidates. While social media adoption rates are growing within these generations, Gen X, Gen Y and soon Gen Z Which bring reluctance to fully embrace social to connect and network both personally and professionally (Adweek, 2018 pp79). Millennial users those who are between 21-34 age, and the impact this could have on brand content. Unlike Millennials, Generation $\mathrm{Z}$ age between 16-20 is actually more likely to be using social media to fill up time and to find entertainment, in touch with employee friends (Criteo, 2018). Above all, Gen Z soon will be imperative to create content capturing all attention in social media. Recruiters also has the sourcing method to build talented implemented for future employees in engaging roles and building passive candidates who haven't applied for current openings. The use of social recruiting to build a strategy that meets the hiring needs and the fulfilling employee's job scope as employee's wants (DiversityMine,2018). Additionally, highly specialized media and communication channels which really help companies in making decisions about employment around the world (Statista, 2018). Therefore, this research can explain which portals are more effective for social recruitment in an employee's job finding (Merrell, 2016). The researchable to investigate the better recruitment channel in Social Recruitment source: as LinkedIn, and Facebook for employees which helps in finding effective employees for the organization.

Source: Jobvite, (2017).

\section{Diagram 1: The Most Use Recruitment Sites}

Q WHICH SOCIAL MEDIA DO YOU USE FOR RECRUITING?

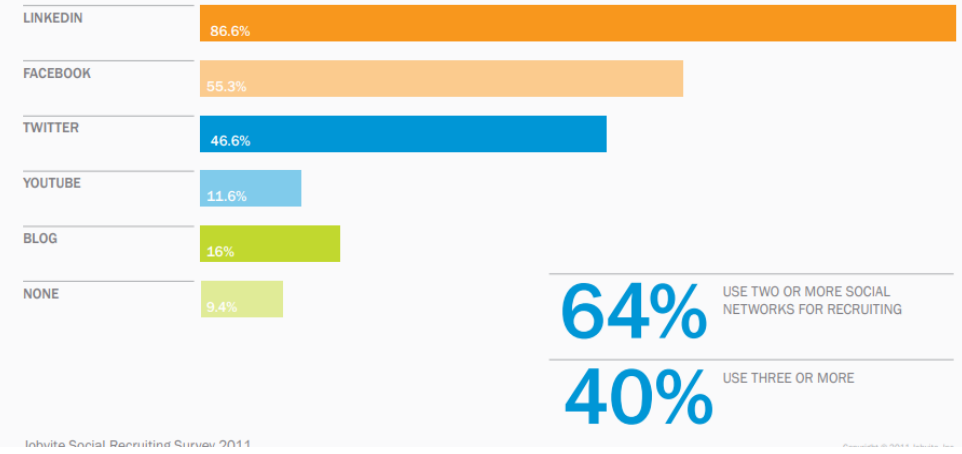




\section{Problem Statement}

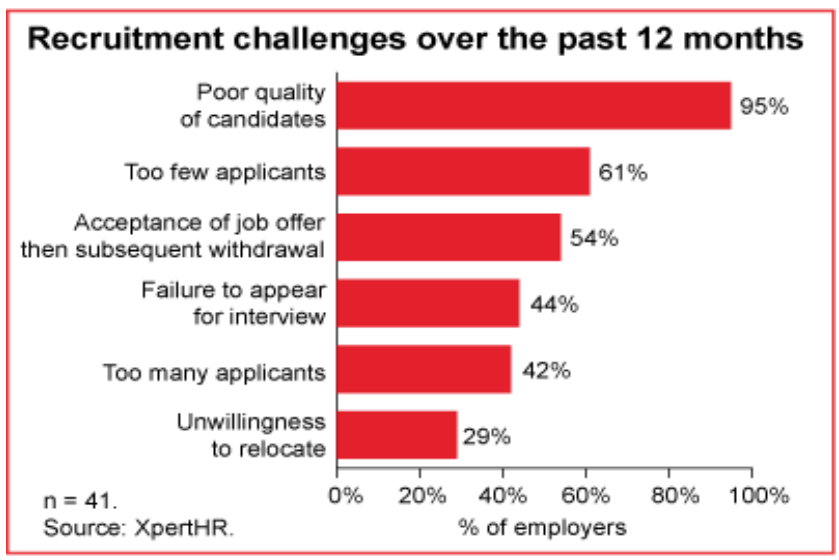

Diagram 2: Challenges of Recruitment in the Modern Era

Source: XpertHr, (2017).

So, in the modern era, Unemployment is still one of the biggest problems in Malaysia. That is because of the people's perception is wider, about traditional recruitment which often used as people applying on applications and resumes, besides compared to people who apply online and companies that use modern interviewing and hiring techniques, such as social media (Paresy, \& Calamaro, 2011). Firstly, the challenges faced often is 95\% of the poor-quality candidate like as applying in the company is traditionally are very less, this happens because people thinking spending time traveling is time-consuming. Secondly, $61 \%$ of the few applicants seek a company job vacancy (XpertHr,2017). Consequently, this drops the number of the candidate applying for the jobs online. Even there are HR managers not receiving resumes from candidates with enough experience to being unable to shift through applications effectively. Besides it also takes long periods of time sorting through the applications, especially through online.

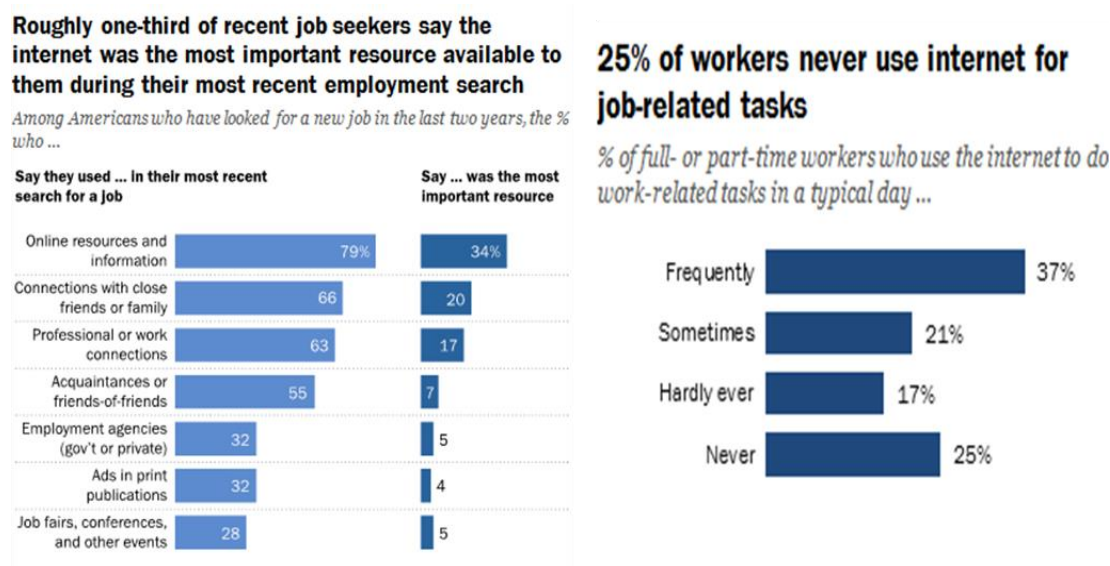

Source: Mark, (2015).

\section{Diagram 3: Job Seekers with Social Media}

There are surprising facts of social recruitment challenge where there is high about $47 \%$ of not clear information on e-recruitment then traditional recruitment brings more possibility of misconceptions and delayed replies (Malinowski, \& Weitzel, 2012). Moreover, the statistics show on use of internet in Employment Agencies and Job fairs search is only 5\%, while other 
research shows the highest is $37 \%$ frequently use and $25 \%$ are never use social sites for employment search which clearly shows biggest challenge is the career blogs are not effective enough to share interactive information for candidates (Undercover Recruiter,2018).

\section{Research Objective}

RO1: To examine the effectiveness of Facebook Recruitment for employees in Job findings.

RO2: To examine the effectiveness of LinkedIn Recruitment for employees in Job findings.

\section{Research Question}

RQ1: What are the outcomes of Facebook Recruitment for employees for employees in Job findings.

RQ2: What is the relationship between effective LinkedIn Recruitment for employees in job findings.

\section{Hypothesis}

H1: There is a positive relationship between Facebook Recruitment for employees in job findings.

H2: There is a positive relationship between LinkedIn Recruitment for employees in job findings.

\section{Significant to The Study}

\section{Advantages for Employers}

Recruitment in social media able to obtain the candidates primarily from the candidate's resume and able to check employee working experience and expected requirements (Reiners \& Alexander, 2013, pp. 4576-4585). Moreover, it also has easy access in both national and international applicants in finding candidates. The webpage has the features to filtered and standardized according to the companies needs in manpower (Clark, 2010). Besides, the company other first concern is the cost of expenses which spend to advertise are high. While some social media such as Facebook, Twitter are low cost and free of charge (Davison,2011).

\section{Advantages for Jobseekers}

Anonymously, using social media sites for job finding have easy access to companies post like responsive job vacancy updates through emails and messages (Girard, 2010). Also, job seekers can easily access information about the company, training program and skill requirement. It also benefits jobseekers to prepare better resume according to the requirement of the companies. For example, the job seekers set of skills, experience or capabilities are the set of requirements for the specific job, which is for jobs seekers to find and meet the vacancy that the company offers (Fallery, 2011 pp. 59-68).

\section{Literature Review}

\section{Definition of Terms}

\section{Social Media}

Social Media refers to most pleading application websites for young people. Social media define as the sites that help in interacting with one another and, have virtual communication, exchange profiles and broaden employee scope of interaction (Smaldone \& Fennoy, 2013). For an organization, it's a huge platform to post information, according to the statistics, Facebook 
is dominating landscape majorities of adults uses. Similarly, $78 \%$ of Malaysian in this age group (15-35) uses Facebook and close to half (45\%) are Twitter users (Hoffman, 2010). So, in this case, social media beneficial in granting interviews, Question, and Answer, Job Screening, Job posting or even Information Collection (Penner,2005). Well, Social media in this generation $\mathrm{Y}$, it is being the favorite tool of motivations drive which connects, create, consume and control. Social media allow establish the social brand, network with people online, identify job opportunities and encourage users soliciting and attracts talented candidate for an organization (Fodor,2010).

\section{Social Media Recruitment}

Social Media Recruitment is the process of using Internet access to actively seek and recruit talented candidates for an organization (Day, \& Landon 2013). This social media platform consists of readily available job boards, specialized business networking sites, and other forums, which enhance in the collection the size of the potential candidate pool which benefits in increasing exponentially for organizations everywhere. Furthermore, Social media recruitment knows as Social Networking Sites (SNWs) which know as internal recruitment such as Job posting \& Employee Referrals or etc (Connerley, \& Carlson, 2009). In this generation Y, it is called fastest growing sites as E-Recruitment, where the organization hiring the potential candidates for the vacant job positions, using the electronic resources, particularly through the internet (Breaugh,2016). The constant change of social media in this century, having a strong presence which can be a positive rise for both job seekers or companies who wants to view information about other candidates or job vacancy (Ballantyne, 2009).

\section{Facebook Recruitment}

Facebook is an American online social media or social networking site that the company used for recruitments internally in companies. There are 20 billion active users, $66 \%$ of whom $\log$ in daily and most popular with the 18-29 age group (Shroeder, 2010). Facebook is one of the large social networks provides a wealth of information for potential candidates, even if not actively seeking a job. Example, information about current and previous jobs, projects candidates are involved with, membership in professional associations or big companies (Stopfer \& Gosling, 2017). Moreover, Facebook helps explore the patterns and trends shaping the social media landscape like new job posting, interview tips or campaign of companies, or other volunteer commitments (Bing,2011). Moreover, Facebook offers a fantastic targeted advertising platform.

\section{LinkedIn Recruitment}

Since 2002, LinkedIn is known as an online professional networking web page with 380 million participants in 200 nations. LinkedIn has proven to be an incredible assist for anyone looking to make professional connections or find employment, there have been some concerns. This LinkedIn Professional Networking site is being useful in the modern era which brings the advantage of technology through programs. According to past research, LinkedIn is being the big user for specifical design for business and candidate in promoting or advertising on company's vacancy in the posting and it also directly approach the people to find the top talent and interesting companies (Owinski, 2015). In Addition, LinkedIn recruitment has been known as the most popular professional networking. LinkedIn has features which bring a context in searching candidates profile page, on employee skills, employment history and education (Sutherland, 2014). 


\section{Previous Studies \& Critical Review}

\section{Facebook and Social Recruitment in Job Findings}

The previous principal findings on the effectiveness of Facebook Recruitment shows that Facebook at this very basic level at getting a high level of response and much effective than others. Lohse (2013), says that social media recruitment as Facebook can be targeted as of participants in different variable and characteristics such as age, population and sometimes experience. Also, according to Allen, (2017), the research has verified that Facebook has the highest Connectivity, which brings access to the internet and offers everyone in sharing information and strengthening community bonds and creating economic opportunities. Therefore, Bullhorn, (2014), the statistics showed about 80 of the 100 respondents (67\%) mentioned that candidates utilize Facebook as a tool job finding. Though Steinfield, (2014) says that Job posting on Facebook as the highest potential almost exclusive ideas in building professional relationships. In this case, the results based all the previous studies, the Hypothesis tested shows significant p-values below $0.05(\beta=0.419)$, which presents that Facebook has the highest significant than other social sites (Ramo,2012).

Moreover, Facebook Sites are also an inexpensive and relatively high-quality alternative (Baltar \& Brunet, 2012). However, Facebook overall used in increasing communication and influence potential employees to lead the number of applicants of a company can receive online. In addition, this has lead Facebook in the positive impression of the organization to exercise among the young generation in the future (Salganik \& Heckathorn, 2014). And as a fact Job seeker are likely to follow the career pages of industry-specific companies (Batterham, 2014). On a global level, the market leader in the American social network Facebook, in fact, the first social media platform, which is useful to the companies to have efficient social media recruitment enabling them to find candidates faster and at a lower cost since using most social tools free of charge (Anna,2018). As an example, Facebook careers such recruitment process ale to find post job opportunities on your Facebook in business page for free and help potential employees have the chance to learn about business and the job opportunity before applying, ensuring that you get informed job applicants.

\section{LinkedIn and Social Recruitment in Job Findings}

On the previous studies that found LinkedIn Social Media Recruitment for Employees in Job findings are being one of the most preferred sites and method effective recruitment. There are observational studies by Nikolaou (2014) which says that LinkedIn is (marginally) even stronger as in this timeline while its discovered Generation Baby Boomers are less likely using social sites. Besides, a study by Houran (2017) shows that LinkedIn for the recruitment purposes has confirmed a positive effect in use LinkedIn are more reckless, effective that companies tend to use sites officially in posting job requirements. Furthermore, a sample study by Caers \& Castelyns, (2011), where LinkedIn is one of the outsourcing sites that successfully has a positive impact among new people as the technology grows. Caers (2011), stated that LinkedIn has the highest convention recruitment platform that $67 \%$ more efficient ( 8 of 10) places advertisements on LinkedIn, rather use it to search for potential candidates to approach for positions. So basically, all the study participants indicated that among all the recruitment sites, Nikolaou (2014) that LinkedIn has the positive relationship in employee's job finding, which has resulted as shows significant p-values below $0.05(\beta=0.379)$ considered to be more effective for recruitment and screening purposes comparing to other sites (Madera, 2012). LinkedIn portals, which easily helping in attracting fresh graduates often practical fill positions in the organization (Ovadia, 2011). 


\section{Related Theories \& Critical Review}

\section{Millennials' Social Behaviours within a Social Media Context}

Weber Shandwick Seattle, (2012) says that survey taken among the Millennials were major usage in the social media $75 \%$ of entire social media usage. Moreover, it also clearly explains that Generation $\mathrm{Y}$ who is being powerful and unique in the square with a larger innovation future of baby boomers (Bucic \& Farris 2012). Furthermore, Alison Henderson, (2010) supports that these developments of social media have several tools in monitoring social media presence for opportunities to connect with potential employees.

\section{Media Richness Theory}

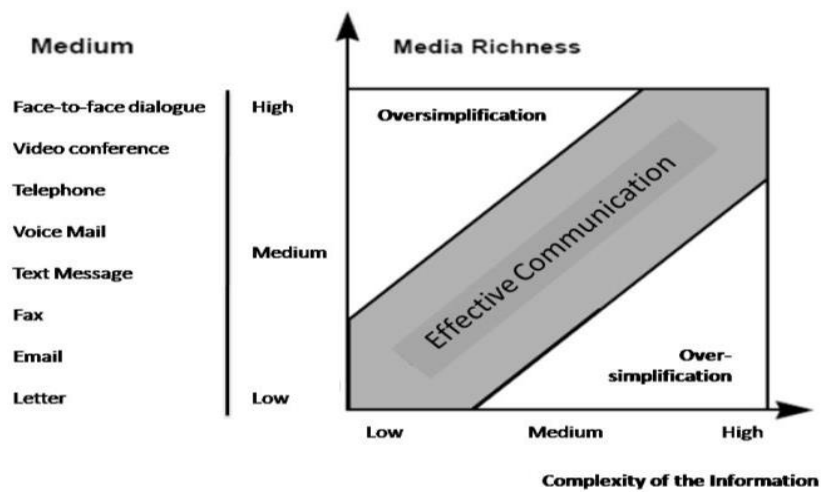

Source: Kessler. (2018).

\section{Diagram 5: Media Richness Theory}

The diagrams explain that use of rich media has effective complexity of the information, communication, and overcomplication (Dennis,2016). Framework above, approaching on the communication based where, interacting complexities that challenge much organization but not social media as one of the tools of easy complexity which brings a strong theoretical approach of the technological breakthroughs (William,2013). Media Richness Theory provides a framework for describing a communication medium's ability to reproduce the information sent over it without loss or distortion. The framework explains on a medium platform of communication such as emails, fax, letter or voicemails helps the complexity of information like face-to-face communication, phone communication, Print Media or other broadcast media. According to Trevino, (2006), the traditional method of recruitment in this era effective and increases job visibility, where the company able to advertise the job vacancy on magazines or newspaper (Gerloff, \& Muir,2015).

\section{The critical theory of Millennials' Social Behaviours within a Social Media Context \& Media} Richness Theory

The criticism of theory, summarizing these two approaches, are effective but the most suitable is Millennials' Social Behaviours within a Social Media theory, which has the positive effects among the social media recruitment especially in term of generation Y (Daft, \& Lengel, 1986). This Generational Theory describes a recurring cycle of age cohorts called 'generations' with specific patterns of behavior that are regarded of information among the two theory has the right intention but the Media Richness Theory using the traditional way of posting information such as emails, fax, letter or voicemails which is less effective in this generation where social media is part of the technology surprise of delivering information through the latest social 
media sites (Suh, 2005).

\section{Research Framework}

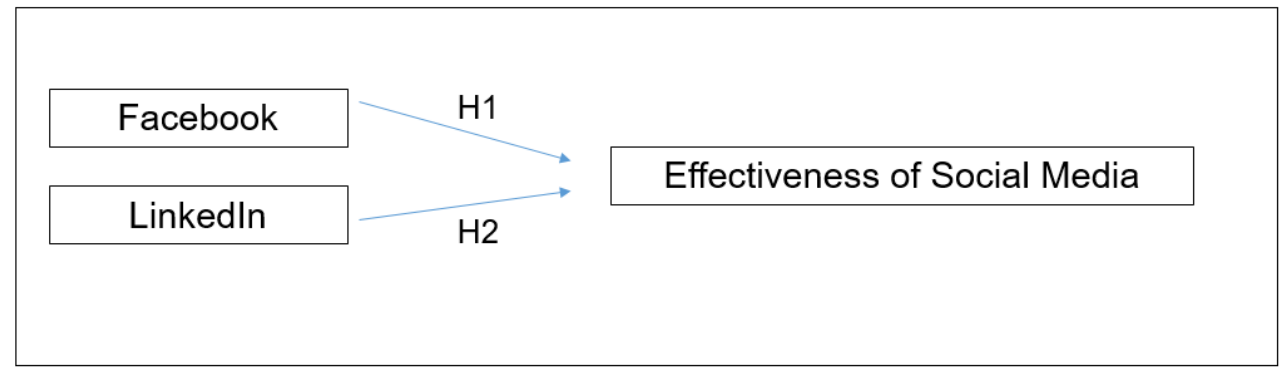

Diagram 5: Framework of Effective Social Recruitment Source in job Finding Source: Social Recruiting, (2018)

There are three main theatrical frameworks that have been used as the tool of social recruitment analysis in the research. These are the social sites as LinkedIn and Facebook. The theoretical helps in understanding the previous study and helps to investigate the effectiveness of social recruitment channel in job findings among the generation Y (Fresh Graduates).

\section{Research Methodology}

\section{Research Strategy}

Coherently, this research has two different strategies; inductive and deductive approach. Firstly, Inductive Strategy is a collection of data to understand strategy in context of patterns, new ideas and existing theory (Clare, 2011). Secondly, Deductive Strategy is based on the optimal learning and which has illustration and demonstrates ideas by supporting hypotheses on relating theories which existed. According to chapter 2 literature review and theoretical framework was executed using a deductive approach while, inductive approach, in a collection of information data interims of contents, supported with percentages and diagrams (Willis, 2018).

\section{Research Design}

Mixed Methods Research, which has explored on the Qualitative Method (concepts definitions, characteristics, and data collection through emails) and Quantitative Method (discovering social problems, measurable information, comparison, statistical facts, and study designs). Though, "mixed methods" most preferable in developing a methodology research that develops valid information collecting and analyzing with of both quantitative (closed-ended) and qualitative (open-ended) data for an effective report (Thornhill, 2017).

\section{Exploratory \& Conclusive Research Design}

Exploratory research means open ask questions on the contemporary problems. Secondly, conclusive research is information that is useful in facts on the hypothesis with numerical measures (Saunders, Lewis, and Thornhill, 2017).

\section{Descriptive Research}

Descriptive research has a role in gaining situation according to phenomenon that is occurring at a specific place(s) and time such as in observational methods, case-study methods and past theories. 


\section{Cross-Sectional \& Longitude Design}

The research assessed in literature review previously is cross-sectional design, where, the review and theories are used to study and support at the prevalence of social media recruitment among the population chosen (Saunders, Lewis, and Thornhill, 2017).

\section{Population and Sampling}

The aim of the study is among fresh graduates because the most use of social media platform is teenagers, moreover its accessible for fresh graduates from different colleges. In the current study, the sample members who were selected towards fresh graduates with the phenomenon under investigation, sufficient and relevant work experience in the field of social media recruitment. The sample survey was conducted for 200 fresh graduates around Subang Jaya, Selangor. The research was conducted into two different techniques which are probability and non- probability in diverse ways to discusses techniques of sample size determination (Clare, 2011). This sampling chooses in small sample sizes and two techniques are chosen convenience and judgmental sampling techniques. Firstly, Convenience sampling is rapidly convenience and easily targeted fresh graduates. Secondly, Judgmental sampling is a strategy of specific measures to obtain information and it's based on literature review theories of ideal for exploratory research design (Thyer, 2010).

\section{Instrument and Measurement}

The questionnaire purpose is to find the effectiveness of social media recruitment among fresh graduates. The questionnaire measures current attitudes and practices in implementing social networking sites for innovative recruitment in the future. Firstly, the instrument was structured in Likert scale measurement ranging from "Strongly disagree" (1), "Disagree" (2), "Neutral" (3), "Agree" (4), and "Strongly agree" (5). The questionnaire, 3 pages long, was divided into 2 sections. It included close-ended questions and five (5) open-ended question. The questionnaire has two (2), Sections A was labeled 'Demographics' which consist of personal information such as gender, age range, average time spent on social media per day, use social media, and valuation on the popularity of social media recruitment platform in the current era. However, Section B was on social media recruitment and (3) different social networking question divided such as Facebook and LinkedIn Recruitment.

\begin{tabular}{|c|c|c|c|}
\hline No & Item & Scale & Source \\
\hline 1 & Facebook & $1-5$ & Claudia, (2014) \& Kroeze, (2016) \\
\hline 2 & LinkedIn & $1-5$ & Joseph, (2012) \& Felicia, (2016) \\
\hline 3 & Social Media Recruitment & $1-5$ & Wolmer, (2012) \& Gerine, (2010) \\
\hline
\end{tabular}

Table 1: Constructive Instrument Questionnaire

\section{Data Collection Method}

The researcher applied two methods of data collection techniques. This research is collect adequate and relevant data to address the research objectives of this study. Nonetheless, the researcher used qualitative research method. The researcher designed a survey questionnaire to collection information on social media recruitment process among fresh graduates (Clare, 2011). The research instrument was used are SurveyMonkey.com. where the questionnaire sent online to 100 respondents through electronic mail and social media. Hence, about another 100 questionnaires were distributed to students Subang Jaya colleges and Universities. Upon trial, the questionnaire could be answered within 3 - 5 minutes. And the time being framed is from 3-5 working days. 


\section{Data Analysis}

The above research was in secondary data which adapted from books, previous thesis, journals, and articles. Well, other data is primary data which will be collected from a questionnaire distribution (Joyner,2015). The research also uses SPSS Software as the supportive analysis which able to analysis on central tendency, normality, reliability, and person correlation and regression.

\section{Central Tendency}

Central tendency is defined as the statistical measure which used to illustrate the descriptive analysis in every value of data representation. It's basically measuring the averages such as the number of frequencies, Mean, Median and Mode with additional standard deviation (Pettaway \& Sandar,2016).

\section{Normality}

Normality is the test of descriptive statistics on determine data is normally distributed or whether the data is analyzed, represented evenly. Besides, Normality test method based on the Skewness and kurtosis which help in findings the strength and limitation of research by precise the decision and the method is based on the standard error (SE) of Skewness and Kurtosis (Waller, 2015). Statically, two numerical measures of shape are skewness is between -0.1 and 0.1 and kurtosis - 0.1 and 0.1. Which sums, skewness and kurtosis values for the responses indicates an approximately normal range (Raj, 2010).

\section{Reliability}

Reliability concerns on the measurement which provides stable and consist result in scaling and measuring reliability responses by utilizing the Cronbach's alpha (Cox, 2013). Cronbach's Alpha is a convenient test used to estimate composite score and it helps measure the limitation on sample size which influence the result (Oragan, 2017).

\begin{tabular}{|c|c|} 
& Cronbach's Alpha \\
\hline$\alpha \geq 0.9$ & Excellent Significant \\
\hline $0.7>\alpha \geq 0.8$ & Good \\
\hline $0.5>\alpha \geq 0.6$ & Acceptable \\
\hline $0.4>\alpha \geq 0.5$ & Poor \\
\hline $0.4>$ & Rejected \\
\hline
\end{tabular}

Source: Oragan, (2017).

Table 2: Rule of Thumb of Cronbach's Alpha

\section{Correlation}

Correlation is the relationship between two or more variables and varies with the other in the same or the opposite direction. Correlation has two variables in a perfect linear relationship, the correlation coefficient will be either 1 or -1 , the result is based on the variables are positively or negatively related (Gopalia, 2012). While If the correlation coefficient is 0 if there is no 
linear relationship between the variables. However, if the p-value is less than 0.05 is accepted while higher than 0.05 is rejected (Harris, 2015).

\begin{tabular}{|c|c|c|c|}
\hline $\begin{array}{c}\text { Size } \\
\text { of Correlation }\end{array}$ & Correlation Interpretation & $\begin{array}{c}\text { Size } \\
\text { of Correlation }\end{array}$ & ation Int \\
\hline 90 to 1.00 & Excellen & -0.90 to -1.00 & $\begin{array}{l}\text { Excellence Negative } \\
\text { Correlation }\end{array}$ \\
\hline .70 to 0.90 & Very & -0.70 to -0.90 & $\begin{array}{r}\text { Very High } \mathrm{N} \\
\text { Cor }\end{array}$ \\
\hline 0.50 to 0.70 & High Positive Correlation & -0.50 to -0.70 & High Negative Correlation \\
\hline 0.30 to 0.50 & Moderate Positive Correlation & -0.30 to -0.50 & Moderate Negative Correlation \\
\hline .10 to 0.29 & Low Positive Correlation & -0.10 to -0.29 & Low Negative Correlation \\
\hline 0.00 & Weak Positive Correlation & -0.00 & Weak Negative Correlation \\
\hline
\end{tabular}

Source: Ventura \& Bringula (2013).

Table 3: Rule of Thumb of Correlation

\section{Ethical Issues of Research Process}

In this section, the research focuses on reviews, activities, articles, and other experimentations materials under ethical attitudes to ensure a good manner in addressing the following ethical considerations (Hennessy, 2012).

\section{Plagiarism}

This paper has occurred on the first stage of proposing information search in different context and information finding. However, plagiarisms are being overserved with authorship and cited with article reviews to avoid presenting unpublished work as the theories and concept, data and finding on graphs and tables. This research includes the literal copying of paraphrasing and the privileged information. Despite, ethically, all the source is avoided by answerable referencing and acknowledgment by authorship, with citation, referencing and attached appendixes (Fiona \& Davis, 2014).

\section{Fabrication and Fasciation}

The second stage is on methodology especially in fabrication with samples addition data, observations, experiment runs. While on the Falsification, all the data information is changed and support claims with hypotheses, other data (Fanelli, 2015). So, basically, all studies are exposed, with questionable research practices, and it's supported with genuine research with authors citation and researchers' reference.

\section{Faulty Data Gathering Procedures}

On the third stage, primary data collection involves human subjects, researchers, documentation, or quantitative, qualitative in measuring the research. That's is why all the data information is established with cases justification of author as "according to the researcher" and "statistics show of researcher" to state that all the data researched in conducted with researcher's authority (George,2013).

\section{Poor Data Storage and Retention}

On the fourth stage is involving the collection of data from interaction and access to identifiable private information. This involves collection of information from respondents are kept private 
and confidential and all the information shared is recorded and attached in the assignment. Moreover, all the part of review and adoption includes such as surveys and questionnaires, from past research and the questionnaire data collected are cited.

\section{Misleading Authorship}

On the fifth stage, the misleading authorship happens when the research shows that publication did not occur as referenced whereby, ethically all the inclusion contents of literature and data collected is basis with truth and honestly acknowledge with researcher's citation and reference by claiming the work is adopted form the original author (Craddick, 2013).

\section{Sneaky Publication Practice}

On this last stage of the research, all the data, information, context, pictures, graphs and charts are published and prepared by the editor are cited with author source. With respect, all the priority of the primary publication is shown in the reference and manuscript based on the research purposes and analytic study (Whitney,2018). In end, all the research tools online and books are used for information content which used ethically and legal to construct any information. Hence, the facts from past researched contents and implicates with informed consents with acknowledgment references.

\section{Limitation of Research Study}

One of the main research limitations faced is the selection of theories sites where the context is larger and in exploring the contents were lack of compatibility between social media recruitment and traditional recruitment selection. Besides, unavailability of specific articles in the field of social media recruitment while other research has used old referencing. Still, there is a confusion of information source, which the first researcher shows the negative relationship and positive relationship the confusion reliability of results of previous studies. Furthermore, lack of previous methodology studies, in the research on websites where it took much time to adopt the findings and evolving the problems to narrow the requirement.

\section{Data Analysis}

\section{Central Tendency Analysis}

\section{Gender Of Respondent}

Statistics
\begin{tabular}{|ll|r|}
\hline Gender & \\
\hline N $\quad$ Valid & 200 \\
& Missing & 0 \\
Mean & 1.57 \\
Median & 2.00 \\
Mode & 2 \\
Std. Deviation & .497 \\
\hline
\end{tabular}

\begin{tabular}{|ll|r|r|r|r|}
\multicolumn{7}{|c|}{ Gender } \\
\hline & & Frequency & Percent & Valid Percent & $\begin{array}{c}\text { Cumulative } \\
\text { Percent }\end{array}$ \\
\hline Valid & Male & 87 & 43.5 & 43.5 & 43.5 \\
& Female & 113 & 56.5 & 56.5 & 100.0 \\
& Total & 200 & 100.0 & 100.0 & \\
\hline
\end{tabular}

Table 4: Central Tendency on Gender of Respondent

According to Table 4, there is a total of 200 respondents, in which $113(56.5 \%)$ are female respondents and $87(43.5 \%)$ are male respondents. The percentage shows that female respondents are much higher than male respondents. 


\section{Age of Respondent}

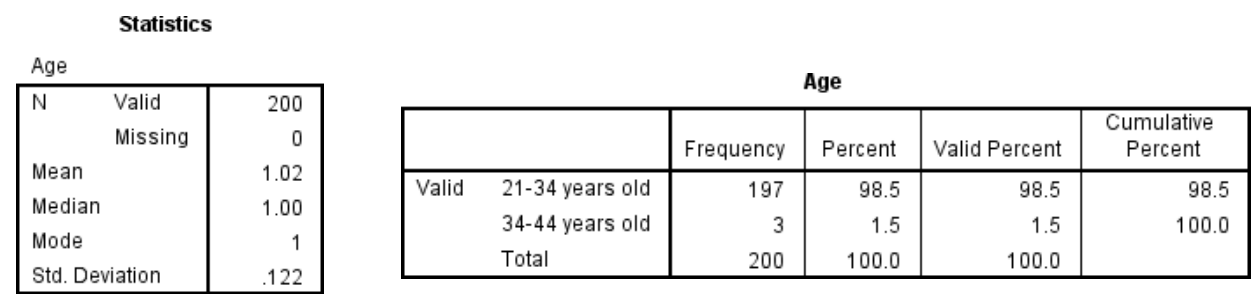

Table 5: Central Tendency on Age of Respondent

According to the Table 5, the statistics on central tendency explains two different age generation which Generation $\mathrm{Y}$ and $\mathrm{X}$. Based on statistics, mean shows at 1.02, median at 1.00 and the mode is at 1 respectively. In this study, most of the respondents are, age group between 21-34 years old, $98.5 \%$ are highest, followed by the minority of age group, between 34-44 years old, $1.5 \%$ is lowest.

\section{Average Time Spends on Social Media Per Day}

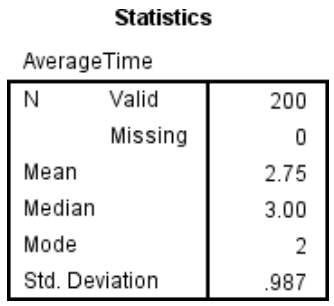

\begin{tabular}{|c|c|c|c|c|c|}
\hline \multicolumn{6}{|c|}{ Average Time } \\
\hline & & Frequency & Percent & Valid Percent & $\begin{array}{c}\text { Cumulative } \\
\text { Percent }\end{array}$ \\
\hline \multirow[t]{5}{*}{ Valid } & less than 30 minutes & 19 & 9.5 & 9.5 & 9.5 \\
\hline & About $30-60$ minutes & 72 & 36.0 & 36.0 & 45.5 \\
\hline & More than $1-2$ hours & 50 & 25.0 & 25.0 & 70.5 \\
\hline & More than 2 hours & 59 & 29.5 & 29.5 & 100.0 \\
\hline & Total & 200 & 100.0 & 100.0 & \\
\hline
\end{tabular}

Table 6: Central Tendency on the Average Time Spends on Social Media Per Day

According to Table 6, the measure of average time spends on social media per day by fresh graduates. Statically the mean is at 2.75 , median about 3.00 and the mode is 2 respectively. The highest time usage is about $30-60$ minutes, about $36 \%$ percentage. Besides, the second highest $29.5 \%$ choose more than 2 hours. While, $25 \%$ who chooses more than 1-2 hours, and the least number of respondents chooses less than 30 minutes. This clearly indicates, that fresh graduates actively, use a social media platform to explore information and communicate.

Which Social Media Platform Do Respondent Use The Most?

\begin{tabular}{|c|c|c|c|c|}
\hline & & \multicolumn{2}{|c|}{ Responses } & \multirow{2}{*}{$\begin{array}{c}\text { Percent of } \\
\text { Cases }\end{array}$} \\
\hline & & $N$ & Percent & \\
\hline \multirow[t]{5}{*}{ \$SocialMedia ${ }^{\mathrm{a}}$} & Facebook & 114 & $22.0 \%$ & $57.3 \%$ \\
\hline & Twitter & 90 & $17.4 \%$ & $45.2 \%$ \\
\hline & Company Websites & 99 & $19.1 \%$ & $49.7 \%$ \\
\hline & Linkedln & 76 & $14.7 \%$ & $38.2 \%$ \\
\hline & Instagram & 139 & $26.8 \%$ & $69.8 \%$ \\
\hline Total & & 518 & $100.0 \%$ & $260.3 \%$ \\
\hline
\end{tabular}

\begin{tabular}{|c|c|c|c|c|c|c|}
\hline \multicolumn{7}{|c|}{ Statistics } \\
\hline & & Facebook & Twitter & $\begin{array}{l}\text { Company } \\
\text { Websites }\end{array}$ & LinkedIn & Instagram \\
\hline \multirow[t]{2}{*}{$\mathrm{N}$} & Valid & 200 & 200 & 200 & 200 & 200 \\
\hline & Missing & 0 & 0 & 0 & 0 & 0 \\
\hline \multicolumn{2}{|c|}{ Mean } & 1.43 & 1.55 & 1.51 & 1.62 & 1.31 \\
\hline \multicolumn{2}{|c|}{ Median } & 1.00 & 2.00 & 2.00 & 2.00 & 1.00 \\
\hline \multicolumn{2}{|c|}{ Mode } & 1 & 2 & 2 & 2 & 1 \\
\hline \multicolumn{2}{|c|}{ Std. Deviation } & .496 & .499 & .501 & .487 & .462 \\
\hline
\end{tabular}

a. Dichotomy group tabulated at value 1

Table 7: Central Tendency On Which Social Media Platform Do Respondent Use The Most

According to Table 7, it explains various types of social media in the current era, which respondent chooses more than 1 option. According to the statistics Facebook mean is 1.43, median about 1.00 and mode is at 1 . Besides, Twitter means the measure is 1.55 , median about 1.55 and mode is 2.00 . Other platforms reported as, company websites mean is at 1.51 , median Copyright $\odot$ GLOBAL ACADEMIC EXCELLENCE (M) SDN BHD - All rights reserved 
about 2.00 and mode is 2.00 same with Instagram, and mean at 1.31 , median at 1.00 . In this study, most of the respondents choose Instagram 26.8\% and Facebook 22.0\%.

\section{The Use of Social Media}

\begin{tabular}{|c|c|c|c|c|}
\hline \multicolumn{5}{|c|}{ \$UseofSocialMedia Frequencies } \\
\hline & & \multicolumn{2}{|c|}{ Responses } & \multirow{2}{*}{$\begin{array}{l}\text { Percent of } \\
\text { Cases }\end{array}$} \\
\hline & & $\mathrm{N}$ & Percent & \\
\hline \multirow[t]{4}{*}{ \$UseofSocialMedia ${ }^{a}$} & InformationFinding & 133 & $24.1 \%$ & $66.5 \%$ \\
\hline & NewsFeeds & 160 & $29.0 \%$ & $80.0 \%$ \\
\hline & To Find Employment & 137 & $24.8 \%$ & $68.5 \%$ \\
\hline & $\begin{array}{l}\text { Keep In Touch with } \\
\text { Family and Friends }\end{array}$ & 122 & $22.1 \%$ & $61.0 \%$ \\
\hline Total & & 552 & $100.0 \%$ & $276.0 \%$ \\
\hline
\end{tabular}

a. Dichotomy group tabulated at value 1

Table 8: Central Tendency on Why Respondent Uses Social Media

According to Table 8, it explains why the respondent uses a social media platform which the respondent chooses more than 1 option. The statistics mean for Information finding is 1.34, Finding Employment is 1.32, and Keeping in touch with family and friends is 1.39 which known the highest among all and the New feeds is 1.20 which known to lowest. The highest usage of social media is new feeds, about $29.0 \%$, out of $160 / 200$ respondent. And the second highest $24.8 \%$ in Finding Employment hence $24.1 \%$ are Information finding followed by least $22.1 \%$ respondents choose to keep in touch with family and friends.

\section{Normality Analysis}

\begin{tabular}{llllllll}
\hline Variable & N & Minimum & Maximum & Mean & $\begin{array}{l}\text { Std } \\
\text { Deviation }\end{array}$ & Skewness & Kurtosis \\
\hline Facebook & 200 & 1 & 5 & 3.77 & 0.948 & -.220 & .039 \\
\hline LinkedIn & 200 & 1 & 5 & 3.81 & 0.920 & -.151 & .175 \\
\hline $\begin{array}{l}\text { Social } \\
\text { Recruitment }\end{array}$ & 200 & 1 & 5 & 3.82 & 0.890 & -.127 & .682 \\
\end{tabular}

Table 9: Normality Test (Skewness and Kurtosis)

According to Table 9, it observes on the normality test of Skewness and Kurtosis on Facebook Recruitment shows at 0.220 while kurtosis is at 0.039 while for Linkedln data range is at -0.151 and 0.175 . All these data show it distributes normally for this research. This is because these data are within the rule of thumb according to chapter 3 , which is between $-1<\mathrm{x}<1$, therefore the normality test on all the variables are accepted for this research.

Reliability Analysis

\begin{tabular}{lcc}
\hline Variable & $\begin{array}{c}\text { Cronbach's } \\
\text { Alpha }\end{array}$ & N of Items \\
\hline Facebook & .764 & 5 \\
\hline LinkedIn & .801 & 5 \\
\hline Social Recruitment & .798 & 5
\end{tabular}

Table 10: Reliability Test 
According to Table 10, the reliability test on Cronbach's alpha for Facebook Recruitment shows, Cronbach's alpha is at 0.764 , for LinkedIn at 0.801 , social recruitment at 0.816 according to Table 2 .

\section{Correlation Analysis}

\section{Facebook \& Social Media Recruitment}

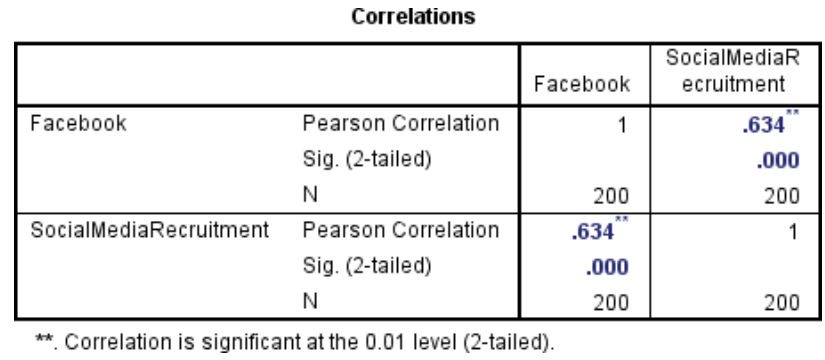

Table 11: Correlation between Facebook \& Social Media Recruitment

According to Table 11, it explains the relationship between Facebook and Social Media Recruitment among fresh graduates in various university and colleges. The data states that the p- value is at 0.000 , accepted because it's less than 0.05 . However, person correlation is at 0.634 which states, there is a high positive relationship between social media recruitment. According to Table 3, data between ( 0.50 to 0.70$)$ is accepted. Therefore, the correlation analysis has a significant positive relationship with awareness of consequences, therefore, $\mathrm{H} 1$ is supported. In the previous study, according to Baltar \& Brunet, (2012), supports that Facebook overall used in increasing communication and influence potential employees because it can be an effective way of obtaining socially, specific age, geographic location, and interests. The past research resulted from p-values below $0.05(\beta=0.419)$, which describes that social nature exhibiting higher levels of the society while, in this recent research is $(\beta=0.634)$, out of 200 participants, which clearly shows it has a positive relationship. Hence, Facebook recruitment has positive relationship therefore, $\mathrm{H} 1$ is accepted.

\section{LinkedIn \& Social Media Recruitment}

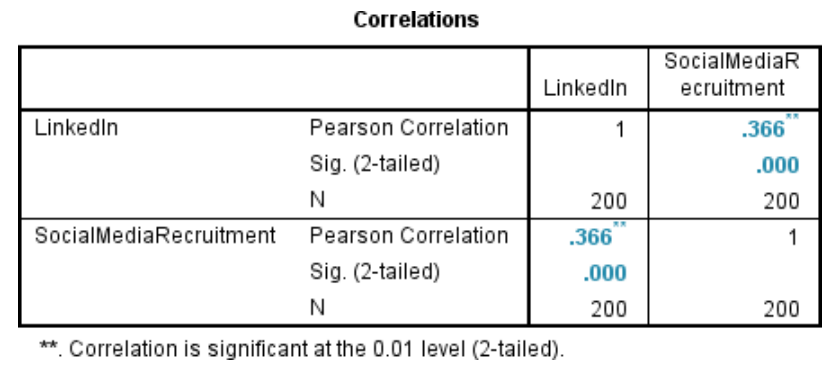

Table 12: Correlation between LinkedIn \& Social Media Recruitment

According to Table 12, it explains the relationship between LinkedIn and Social Media Recruitment which among fresh graduates and students in various university and colleges. The data states that the p-value is at 0.000 is accepted because according to p-value below 0.05 is accepted. In Addition, person correlation is at 0.366 which that explains, there is a moderate positive relationship between social media recruitment. According to Table 3, data between (0.30 to 0.50$)$ is accepted. Therefore, the correlation analysis has a significant positive 
relationship with awareness of consequences, therefore, $\mathrm{H} 2$ is supported.

Nikolaou (2014) that the previous study resulted in $0.05(\beta=0.379)$ considered being more effective which the latest result effectively shows $(\beta=0.366)$ which seems to have positive significant among millennial. Therefore, the hypothesis is accepted because there is a positive relationship between LinkedIn and Social Media Recruitment.

\section{Recommendation \& Conclusion}

For Facebook Recruitment, it is suggested to create a Facebook Career Page to Keep Up with the News in major inbound marketing and implementing a successful Facebook careers strategy to stay up to date on Facebook (Caers \& Castelyns, 2010). Next, provide timely Responses to Engagement. Where this helps job seekers to know that the company is actively responding to the questions, queries, and comments. Besides, Facebook is one of the selling points by Share Plenty of Staff/Office Photos which shows that company culture of boosting employee cultural diversity in the workplace (Gregoire,2014). Other than that, "Live Video" on Facebook also very interactive and attract many fresh graduates to form online. This ability to send a message to the community to learn and discover what new company giving out (Kuhn, 2016).

For LinkedIn Recruitment, it is suggested to create company profiles are a good way to glean at-a-glance information on a company in which employee interested. Company profiles provide an excellent window to connect with the company, past, current, and future projects. So, there are most of the incredible recruiting resource firstly, suggesting LinkedIn Recruitment improve in use visuals and banners showcasing the employees and distinct company culture traits. This technique uses crisp, clear images to the company talent brand and enhances a wider variety of professions by inviting members to view a real-life glimpse into a day in the life of the company employees (Sloka, 2015).

In addition, company websites Recruitment presents could also provide huge opportunity to establish every industry expertise and extend audience reach through social sharing. Firstly, sharing activities happening online by drench up information, resources, learning, and development or future careers, and job opportunities in real time (Parry, \& Tyson, 2018). Besides, organization are encouraged to provide diversify Information as" There is much fish in the sea, but candidates are caught with different techniques" as an attractive way of providing information on career advice, in such information transition of college to career, career tips, skills, positions, employee spotlights, interviews, experience, company, programs, initiative and reward as employer of Choice Awards. Even Company blogs can provide compelling stories from employees to fresh graduates such as in work- life tips, career posts and personal stories like enabled not disabled (Parry \& Wilson, 2009). The inbox option can be helpful in sharing information on the company career site landing page, job descriptions, opportunities, and even career development with training (Sander\& Pauzuoliene, 2015).

Some recommendations have been proposed after analyzing the fact and findings. There were few problems faced by the organization in social media recruitment such as high unemployment, and lack of interaction with recruiters. Hence, according to this research's problem statement, involve in poor quality candidates when recruiting and a smaller number of applicants henceforward, the organization encourages to allow employees to share company achievements such as by sharing interesting, valuable and impressive information about the organization and including successes and thought leadership content. Besides, the organization 
to build company brand considering including some posts about life at the office and employee profiles to attract fresh graduates' attention (Nikolaou, 2014). Therefore, Facebook can be one of branding recruitment sites able to create awareness among those young, exciting corporations to attract and increase the number of people connecting with potential job position to be used for Recruitment.

Overall, new recruitment practices clearly bring new challenges, potentially involving changes in corporate culture. The use online recruitment software's able to recruit people involves cultural and modern transitions. The speed and convenience take a large number of candidates in choosing east way of finding job in current trend. Lastly, it's really matters for current generation on finding potential employee in workplace that is able to improve candidate's professional potential and career path.

\section{References}

Alison Henderson, Rachel Bowley, (2010) "Authentic dialogue? The role of "friendship" in a social media recruitment campaign", Journal of Communication Management, Vol. 14 Issue: 3, pp.237-257, https://doi.org/10.1108/13632541011064517 [Accessed 13 October 2019]

Allen, D. G., Mahto, R. V., \& Otondo, R. F. (2007). Web-based recruitment: Effects of Among Brazilians. Journal of Medical Internet attraction. Journal of Applied Psychology, 92(6), 1696- 1708. [Accessed 3 October 2019]

Anna Q.V, (2018). A regression approach to testing genetic influence on communication behavio...: Discovery Service. [ONLINE] Available at: http://eds.b.ebscohost.com/eds/detail/. [Accessed 26 September 2019].

Baltar, F., \& Brunet, I. (2012). Social research 2.0: virtual snowball sampling method using10/tech/facebook.google.time_1_mark-zuckerberg-facebook-webusers? [Accessed 3 October 2019]

Bing, (2011). Find a Job through Social Networking: Use Linkedin, Twitter, Facebook, Blogs, and More to Advance Your Career. JIST Works [Accessed 1 October 2019].

Breaugh, \& Hoboken, NJ: John Wiley (2016). Employee recruitment: Current knowledge and important areas in Social Media Recruiting Behaviours Advances in Experimental Social Media Psychology, Vol. 27 [Accessed 1 October 2019].

Bucic et al., 2012; Farris et al., (2002). Millennials_Social_Behaviors_within_a_Social_Media_Context_-

_Gender_Differences_Count_Available from: https://www.researchgate.net/publication/262912909_ [accessed Oct 03 2019].

Caers, R. \& Castelyns, V. (2010). LinkedIn and Facebook in Belgium: The Influences and Biases of Social Network Sites in Recruitment and Selection Procedures. Social Science Computer Review, Volume 29, Issue 4, pp. 437-448. 5. [Accessed 1 October 2019].

Caers, R. C. (2011). LinkedIn and Facebook in Belgium: The Influences and Biases of Social Network Sites in Recruitment and Selection Procedures. Adv Physiol Educ. 100-109.

Clare, (2011) Writing Research - Transforming Data into Text. London: Churchill Livingstone. [Accessed 24 October 2019].

Clark and Roberts, (2010). Recruiting 2.0. Entrepreneur, 2, 55-57. Accessed link:http://www.jamk.fi/kirjasto, Nelli-portaali, EBSCO. [Accessed 4 October 2019].

Connerley, \& Carlson, (2009). Evidence of differences in applicant pool quality. Personnel Review, Vol. 32, No. 1, 22-39. [Accessed 3 October 2019]

Cox, A. (2013). The use of social media in the recruitment process. London: ACAS. [Accessed 30 October 2019]. 
Craddick, (2013). Dietary quality assurance processes of the DASH-Sodium controlled diet study.

Journal of the American Dietetic Association, 103(10): 1339-1346. [Accessed 30 October 2019].

Daft, \& Lengel, R.H. (1986). Organizational information requirements, media richness and structural design. Management Science 32(5), 554-571. [Accessed 03 October 2019].

Damaschke, K.C. (2012), "First impression 2.0: competency representation on LinkedIn", available at: http://essay.utwente.nl/61652/1/MSc_K_Damaschke.pdf. [Accessed 21 October 2019].

Davison, H. M. (2011). To Screen or Not to Screen? Using the Internet for Selection Decisions. Springer, 1-21. [Accessed 25 September 2019].

Day, \& Landon (2013). Toward A Theory Of Consumer Complaining Behavior. In A.G. ) for future research. Human Resource Management Review, 18(3), 103-118. [Accessed 06 October 2019].

Dennis, Alan R, (2016)"Media richness and information acquisition in internet recruitment null". Journal of Managerial Psychology. 29 (7): 866-883. 2014-09-02. doi:10.1108/JMP-05-2012-0155. ISSN 0268-3946.) [Accessed 05 October 2019].

Diaby, M. V. (2014). Taxonomy-based Job Recommender Systems On Facebook and LinkedIn Profile. Association Nationale de la Recherce et de la Technologie. Paris. [Accessed 26 September 2019].

DiversityMine. 2018. Gen Y1: A Communication Perspective | DiversityMine. [ONLINE] Available at: http://en.diversitymine.eu/gen-y1-a-communication-perspective/. [Accessed 21 September 2019].

Fallery, (2011) Users of the world, unite! The challenges and opportunities of Social Media, Business Horizons, Vol. 53, Issue 1, pp. 59-68. [Accessed 02 October 2019].

Fanelli D, 2015. How many scientists fabricate and falsify research? A systematic review and meta-analysis of survey data. Plos One. 2009;29: e5738. [Accessed 30 October 2019].

Fiona \& Davis (2014). Plagiarism and punishment. and soul of scientific publication. Indian Journal Orthop. Psychother Psychosom. 2007; 335:7627. [Accessed 30 October 2019].

George, S.L., Barton, F.B., Fairweather, W.R., Honohan, T., Mowery, R, O’Neill, R. (2013). Guidelines for quality assurance in multicenter trials: a position paper. Controlled ClinicalTrials, 19:477-493. [Accessed 30 October 2019].

Gerloff, E. \& Muir, N. (2015). The richness imperative and cognitive style: The role of individual differences in media choice behavior. Management Communication Quarterly, 4(2) [Accessed 05 October 2019].

Girard, A. F. [ONLINE] Available at: http://eds.b.ebscohost.com/eds/detail/ [Accessed 27 September 2018]. [Accessed 25 September 2019].

Glassdoor. 2018. Social Recruiting Strategies | Glassdoor. [ONLINE] Available at: https://www.glassdoor.com/employers/popular-topics/social-recruiting.htm.

[Accessed 19 September 2019].

Gopalia, A. (2012). LinkedIn Effectiveness of Online Recruitment and Selection Process. Oxford Brookes University. [Accessed 30 October 2019].

Gregoire, (2014). Leveraging Social Media to Enhance Recruitment Effectiveness A Facebook Experiment. Internet Research, Volume 24, Issue 4, pp. 474 - 495. 6. [Accessed 1 October 2019].

Harris, (2013). Research on Internet Recruiting and Testing: Current status and future Directions. International Review of Industrial and Organizational Psychology, 16, 131165. [Accessed 27 October 2019]. 
Hennessy K, et al, 2012. Ethics and scientific publication. Adv Physiol Educ. 2005; 29:9-74. [Accessed 30 October 2019].

Hoffman \& Fodor, (2010). The impact of social media on recruitment: Are you LinkedIn? Available:https://www.researchgate.net/publication/325018956_The_impact_of_socia 1_media_on_recruitm ent_Are_you_LinkedIn [Accessed 1 October 2019].

Houran, J. (2017). New HR study: Candid recruitment experiences with LinkedIn. Retrieved April 20, 2017, from http://www.aethoscg.com/aethos_insights/new-hr-study-candidrecruitment- experiences-with-linkedin/https://doi.org/10.1016/j.hrmr.2008.07.003 [Accessed 1 October 2019].

Joyner, R.L. (2015) Writing the Winning Thesis or Dissertation - A Step by Step Guide Second Edition. California: Corwin Press. [Accessed 25 October 2018].

Kuhn, (2016) Importance of the internet to human resource practitioners in Hong Kong. Personnel Review, 37(1), pp.66-84. [Accessed 3 October 2019].

Lohse B. Facebook is an effective strategy to recruit low-income women to online nutrition education. Educ Behav. 2013;45(1):69-76. doi: 10.1016/j.jneb.2012.06.006. Methods in Psychiatric Research. [Accessed 3 October 2019]

Madera, M. J. (2012). Using social networking websites as a selection tool: The role of selection process fairness and job pursuit intentions. International Journal of Hospitality Management, 31, pp. 1276- 1282.

Malinowski, \& Weitzel, (2012). Analyzing the Impact of IS Support on Recruitment Processes: An E-Recruitment Phase Model. International Refereed Journal of Arts Science \& Commerce Research (RW-JASCR), 3 (3(2)), 33-39. [Accessed 3 October 2019]

Mark, H. (2015). Job seekers find internet essential for employment search. [online] Pew Research Center: Internet, Science \& Tech. Available at: http://www.pewinternet.org/2015/11/19/1-the- internet-and-job-seeking/ [Accessed 3 October 2019].

Nikolaou, I. (2014). Social networking web sites in job search and employee recruitment. International Journal of Selection and Assessment, Vol. 22, pp.179-189. [Accessed 5 October 2019].

Oragan, D. (2017). A reappraisal and reinterpretation of the satisfaction-causesperformance.

Academy of Management Review, 46-53. [Accessed 30 October 2019].

Ovadia, S., (2011). An early introduction to the Google+ social networking project. Behavioral and Social Sciences Librarian 30, 259-263.

Owinski, B. (2015). Linkedln's Purchase of Lynda.com Is The Best Money It'11 Ever Spend. Retrieved from http://www.forbes.com/sites/bobbyowsinski/2015/04/13/whylinkedins- purchaseof-lynda-com-is-the-best-money-it-will-ever-spend. [Accessed 2 October 2019].

Paresy, \& Calamaro, (2011) A systematic review of social networking sites: innovative platforms for health research targeting adolescents and young adults. Available at: doi: 10.1111/jnu.12032. [Accessed 3 October 2018]

Parry, E. \&. Wilson, H. (2009). Factors influencing the adoption of online recruitment. Personnel Review, Vol. 38, pp.655-673. [Accessed 5 March 2019].

Parry, E. \&. Tyson, S. (2018). An analysis of the use and success of online recruitment methods in the UK. Human Resource Management Journal, Vol. 18, pp. 257-274. [Accessed 3 March 2019].

Penner, (2005). Worldwide Knowledge Exchange. (2010). White Paper: Millennials And Social Media, Annual Review of Psychology, Vol. 56, pp. 365-392. Retrieved from 
http://144.118.25.24/bitstream/1860/2871/1/Rozaklis-Gasson-Agosto.pdf) [Accessed 06 October 2019].

Pettaway, (2016,) Surveying organizational effectiveness: A case study from the United Arab Emirates. Journal of Organizational Culture, Communication and Conflict. [Accessed 30 October 2019].

Ramo DE, Prochaska JJ. Broad reach and targeted recruitment using Facebook for an online survey of young adult substance use. J Med Internet Res. 2012;14(1):e28. doi: 10.2196/jmir.1878. http://www.jmir.org/2012/1/e28/ Research, 15(3), e48. Retrieved from http://articles.cnn.com/2010-09-. [Accessed 4 October 2019]

Reiners, T. A. (2013). Social network Perception Alignment of E-recruiters and Potential Applicants. 46th Hawaii International Conference on System Sciences, (pp. 45764585). [Accessed 26 September 2019].

Salganik, M. J., \& Heckathorn, D. D. (2004). Sampling and Estimation in Hidden Populations. [Accessed 3 October 2019]

Sander\& Pauzuoliene, (2015). The Difference of Social Network Sites Explained with the Employment Seeking Process. Regional Formation and Development Studies, Issue 17, pp. $145-153$. [Accessed 26 September 2019].

Saunders, M., Lewis, P. and Thornhill, A. (2017) Research Methods for Business Students Fifth Edition. Harlow: Pearson Education Ltd. [Accessed 26 October 2019].

Shroeder, S. (2010). Web users now on Facebook longer than Google. CNN Tech, San Diego California, CA, pp. 271-360) [Accessed 06 October 2019].

Sloka, B. (2015). Use of Social Network Site's Profile for the Employment Seeking Process. In A. Rocha et al., eds. New Contributions in Information Systems and Technologies Volume 1. Springer Berlin Heidelberg, pp. 1023 - 1032. [Accessed 3 March 2019].

Smaldone \& Fennoy, (2013). Journal on Information, Organizational Brand, And Attitudes Toward A Web Site On Applicant International Conference On Supporting Group Work. 95-103. doi:10.1111/j.0081-1750.2004.00152. x. [Accessed 4 October 2019]

Steinfield, (2014). The Benefits Of Facebook "Friends": Social Capital And College Students' Use Of Online Social Networking Sites. Journal of Computer-Mediated Communication, 12(4), 1143- 1168.) [Accessed 07 October 2019].

Stollak, M., Vandenberg, (2014). How social media is influencing the job search process. Journal of Management and Marketing Research, 15, 1. [Accessed 3 October 2019].

Stopfer \& Gosling, (2017) Social Networking Web Sites in Job Search and Employee Recruitment.

Availablehttps://www.researchgate.net/publication/261842249_Social_Networking _

Web_Sites_in_Job_Search_and_Employee_Recruitmen[Accessed 3 October 2019].

Suh, K.S. (2005). Impact of communication medium on task performance and satisfaction: an examination of media-richness theory. Information \& Management, 35, 295-312.

Sutherland, P. (2014). How social media is influencing the job search process. Journal of Management and Marketing Research, 15, 23. [Accessed 3 October 2019].

Thyer, (2010) The Handbook of Social Work Research Methods Second Edition. London: Sage Publications. [Accessed 27 October 2019].

Trevino, (2006). Media Symbolism, Media Richness and media Choice in Organizations. Communication Research, 14(5), 553-574. [Accessed 07 October 2019].

Undercover Recruiter. 2018. 13 Surprising Social Media and Recruitment Facts. [ONLINE] Available at: https://theundercoverrecruiter.com/13-social-media-recruitment-factsvideo/. [Accessed 21 September 2019].

Ventura, \& Bringula, (2013). Effectiveness of Online Job Recruitment System. International Journal of Computer Science, 10(4), 152-159. [Accessed 27 February 2019]. 
Waller, (2015) Institute for Digital Research and Education. (2015). What does the Cronbach's alpha mean? Available at http://www.ats.ucla.edu/stat/spss/faq/alpha.html. . [Accessed 30 October 2019].

Whitney (2018). Quality assurance and quality control in longitudinal studies. Epidemiologic Reviews, 20(1): 71-80. [Accessed 30 October 2019].

William (2013). "The effects of cognitive style and media richness on commitment to telework and virtual teams". Journal of Vocational Behavior. Special Issue on Technology and Careers. 63 (2): 199-219. doi:10.1016/S0001-8791(03)00041-1) [Accessed 05 October 2019].

Willis, J. (2018) Qualitative Research Methods in Education and Educational Technology. Charlotte NC: Information Age Publishing Inc. [Accessed 25 October 2019].

Yeaton, \&Wolf, M. S. (2014). Social Media utilization in Human Resource Management. Research Gate. [Accessed 20 September 2019]. 